Supplement of The Cryosphere, 13, 2281-2301, 2019

https://doi.org/10.5194/tc-13-2281-2019-supplement

(C) Author(s) 2019. This work is distributed under

the Creative Commons Attribution 4.0 License.

(c) (1)

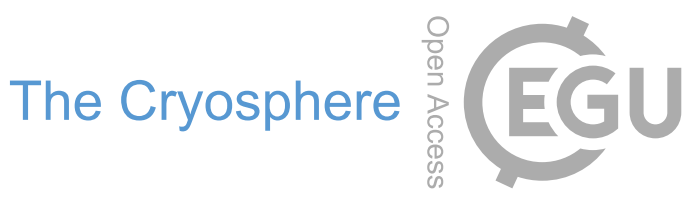

Supplement of

\title{
Modeling the response of Greenland outlet glaciers to global warming using a coupled flow line-plume model
}

Johanna Beckmann et al.

Correspondence to: Johanna Beckmannn (beckmann@ pik-potsdam.de)

The copyright of individual parts of the supplement might differ from the CC BY 4.0 License. 


\section{Supporting informaiton}

\section{Input data of all glaciers}

\subsection{Surface mass balance}
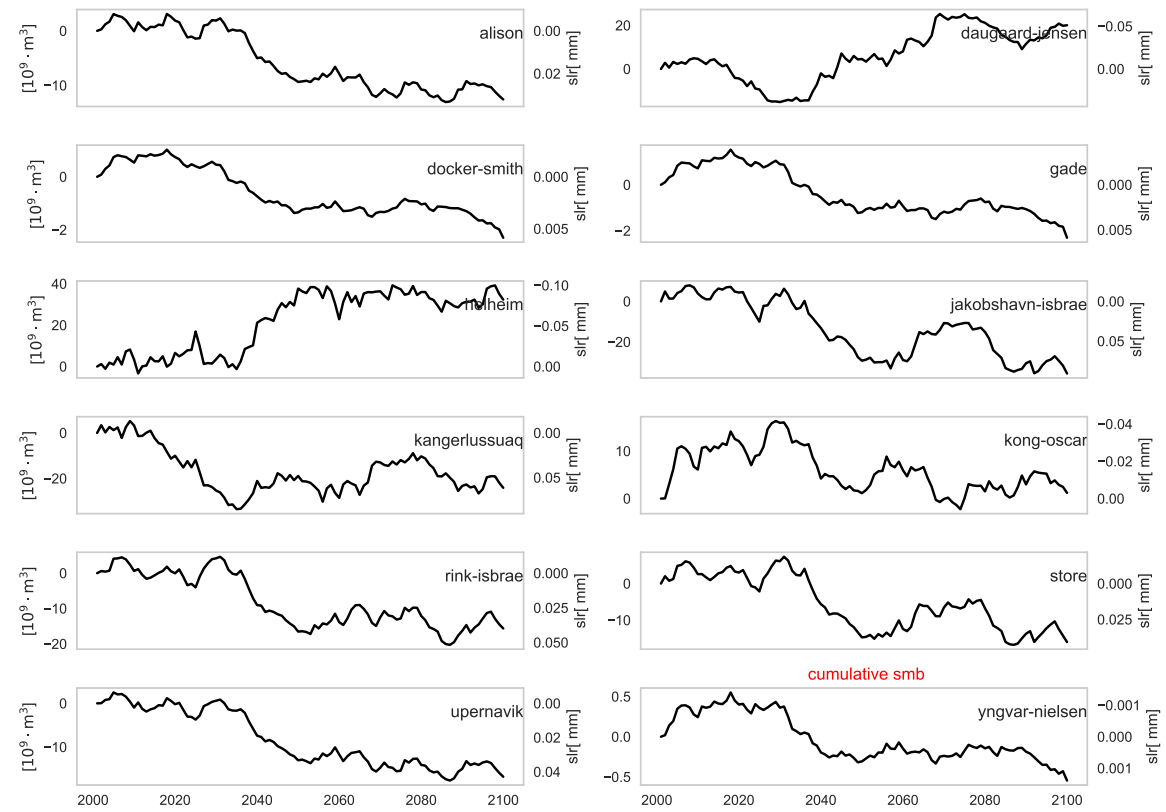

Figure S1. Upper erstimate of the cumulative SMB-forcing from MAR with the CMIP5 MIROC5 model. The forcing was calculated by assuming a constant glacier catchment (no retreat.) 

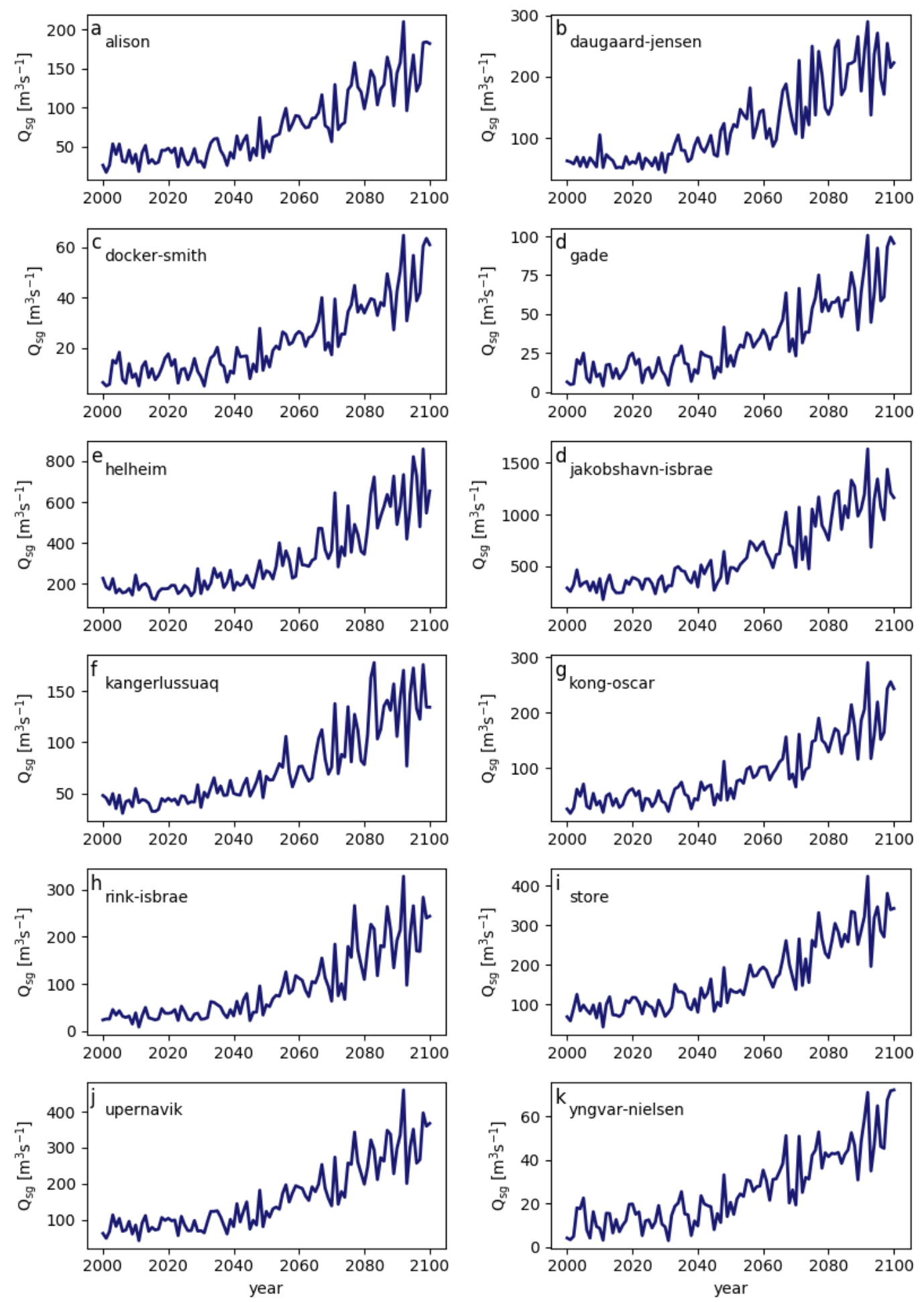

Figure S2. Annual subglacial discharge for each glacier derived by Cảlov et al. (2018) under RCP 8.5 and CMIP5 model MIROC5. 


\subsection{Temperature profiles}
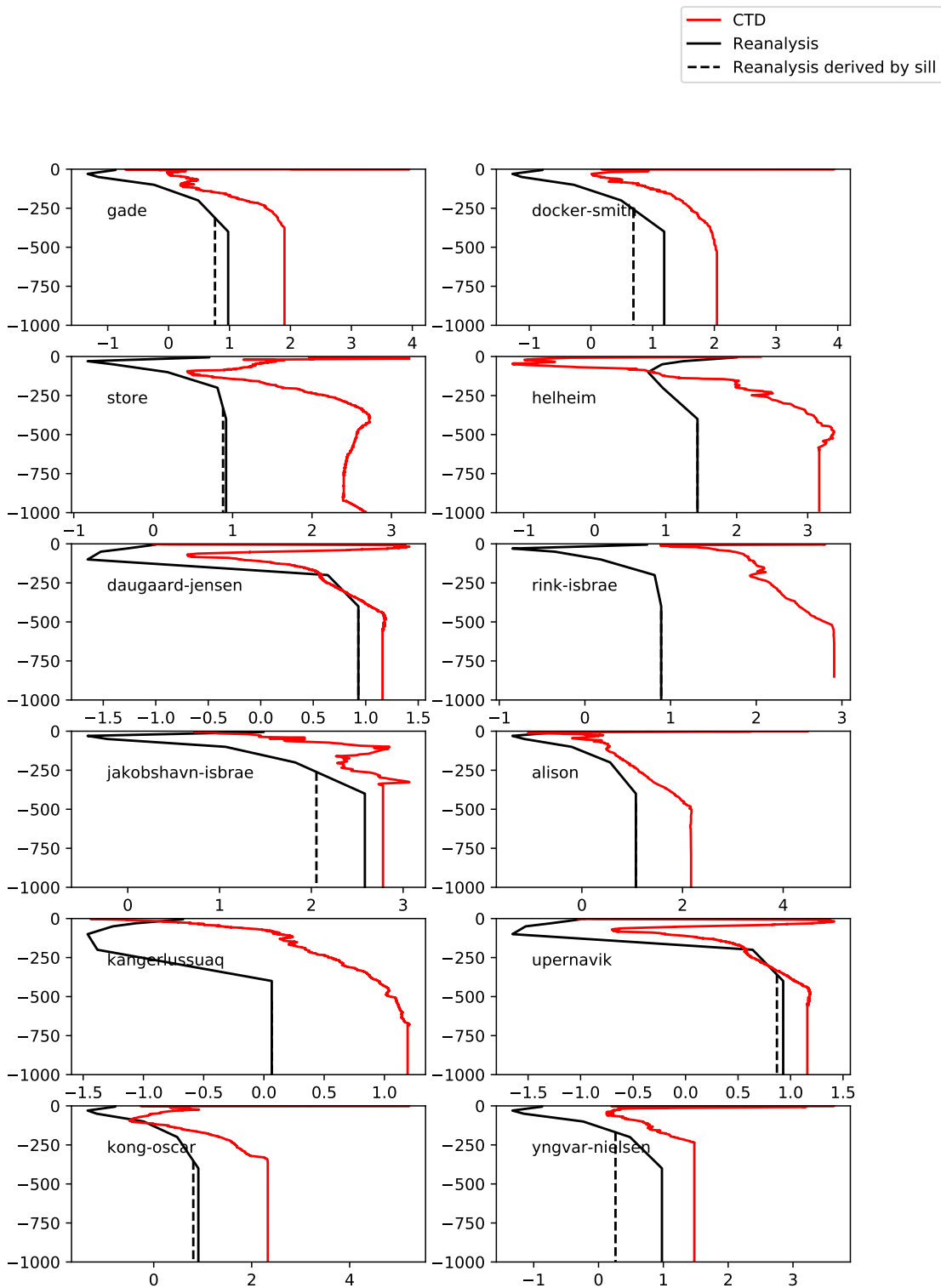

Figure S3. Temperature profiles used in the simulations for each glacier from terminus-close CTD measurements (red) and reanalysis data (black) derived from the 400m-depth point (listed in Tab. S1 ). Reconstructed temperature profile from reanalysis data (black, dashed line.), if the depth of the the shallowest sill within the fjord (derived from the latest Bedmachienev3, Fig. S8 ) would have been considered. 


\section{Construction of the temperature salinity profiles}

We used two temperature salinity profiles for each glacier, one from direct measurements and one derived from the reanalysis data set TOPAZ. The TOPAZ dataset was produced with the ocean model HYCOM using in situ measurements and satellite data sets. It covers the time span from 1991-2013 with a spatial resolution of $12.5 \mathrm{~km}$ and for depths of 5, 30, 50, 100, 200,

$5400,700,1000,1500,2000,2500,3000 \mathrm{~m}$. Below $200 \mathrm{~m}$ depth an error $>1^{\circ} \mathrm{C}$ and $>0.1 \mathrm{psu}$ can occur. The dataset does not resolve the Greenland fjords and covers only the open ocean and continental shelf.

It is known that the vertical T-S profile inside the fjords can resemble the profile in the open sea (Straneo et al., 2012; Straneo and Heimbach, 2013; Inall et al., 2014). However, often the closest grid cell in the ocean reanalysis data which corresponds to the depth of the grounding line can be located hundreds of $\mathrm{km}$ from the fjord mouth, where other ocean conditions might prevail. Figure S4 illustrates this problem for the Kangerlussuaq glacier: CTD measurements below $400 \mathrm{~m}$ show here much colder temperatures inside of the fjord than far outside of the fjord. A calculation with the line plume for a subglacial discharge of $50 \mathrm{~m}^{3} \mathrm{~s}^{-1}$ shows that the melt rate calculated with the TS-profile inside the fjords (50 km away from glacier) and on the continental shelf (200 km away from calving front) gives similar values of $0.5-0.6 \mathrm{~m} \mathrm{~d}^{-1}$ but when the melt rate is calculated using the outermost CTD outside the continental shelf ( Fig. S4 red dot, at $\sim 400 \mathrm{~km}$ distance from the glacier and where the nearest reanalysis data with the $700 \mathrm{~m}$ depth are available) simulated melt reaches $3.6 \mathrm{~m} \mathrm{~d}^{-1}$, i.e. nearly an order of magnitude higher. Thus, choosing temperatures in the open ocean may lead to strong errors of simulated melt rates. The difficulty if the reanalysis data set is, that the grid cells which are deep enough as e.g. the grounding line $(700 \mathrm{~m})$ are located mostly outside the continental shelf in the open ocean. The closest cells are only $200 \mathrm{~m}$ deep and therefore do not represent the temperature distribution in the entire fjord depth. To choose/ construct the "right" temperature profile we first compared temperature-salinity profiles constructed from the reanalysis data to available CTD measurements inside the fjords made near to the glacier fronts. We investigated how to use the reanalysis data from outside the fjords to produce T-S profiles close to observations made inside the fjord. Therefore, we constructed the T-S profiles from reanalysis data by detecting the reanalysis grid-cells closest to the fjord mouth and with the depth of at least 200, 400 and 700 meters. We chose these maximum depths, since they corresponds vertical levels in the reanalysis data set and at the same time represent typical depths of Greenland fjords and glacier grounding lines. Surface temperatures can be strongly influenced by a seasonal signal or other external factors and since they are less important for determine the submarine melt rate, we asses the quality of the constructed T-S profile by comparing with CTDs temperatures at the depths 200, 400 and 700m only. Figure S5 and S6 compare the temperature at these depths from reanalysis data with available CTD profiles measured over past several decades for Jakobshavn-Isbrae and Store Glacier. Since Greenland is surrounded by the continental shelf with typical depths of 200-400 meters, most of the 700-meter depth grid-cells in the

30 reanalysis data are located outside the shelves, far away from the glacier mouth as shown in Fig. S7 on the example of Store Glacier. For Store Glacier, the temperature at 700m depth inside the fjord measured by CTD is much warmer than the temperature in reanalysis data at the same depth but far away in the open ocean, which can potentially be explained by the influence of shallow continental shelf. As Schaffer et al. (2017) showed, for the Nioghalvfjerdsfjorden Glacier, the continental shelf works similarly to a sill that blocks waters from greater depths and favors shallow water masses to pass into the fjord. For all of the investigated glaciers, we found better agreement between temperature profiles constructed from the reanalysis data and CTD if we disregard temperature at $700 \mathrm{~m}$-depth in reanalysis data and use instead temperature at $400 \mathrm{~m}$-depth only mainly located on the continental shelf. If the grounding line depth was deeper than $400 \mathrm{~m}$, temperatures below this depth were assumed to be equal to the temperature at $400 \mathrm{~m}$-depth in the reanalysis data. The corresponding salinity profile below $400 \mathrm{~m}$-depth was modified the same way as the temperature profile. The location of the reanalysis data point is listed in Table S1. To produce a "present-day" reanalysis T-S profile that resembles inside-fjord conditions, we averaged temperature and salinity from reanalysis data over period 1990-2010 in that particular cell. An overview of the the T-S profiles from CTD and constructed from reanalysis data is depicted in Fig. S3 .

The T-S profiles constructed from the reanalysis data, as well as those from the CTD measurements, were used as the

boundary conditions for the plume model. Figure 4 (main test) shows that the temperatures derived from reanalysis data are colder than those from CTD measurements at the grounding line depth for most of the selected glaciers. This bias also remains when choosing temperatures from reanalysis data for the same periods when the CTD measurements were taken (not shown). Similar to the continental shelf, 'blocking' shallow sills in a fjords modify the water masses near the grounding line of a glacier. 
However, the consideration of the sill depth (Fig.S8) when reconstructing the T-S profiles from the reanalysis data only leads to an even stronger temperature bias (dashed line, Fig. S3) towards colder temperatures. Therefore, we always use the reanalysis data from 400m depth to construct T-S profiles irrespective of the sill's depth. We tested how sensitive the model response is to the chosen present-day T-S profile (CTD or Reanalysis) when carrying out future climate change simulations (Section 5, main text and Fig.S11)
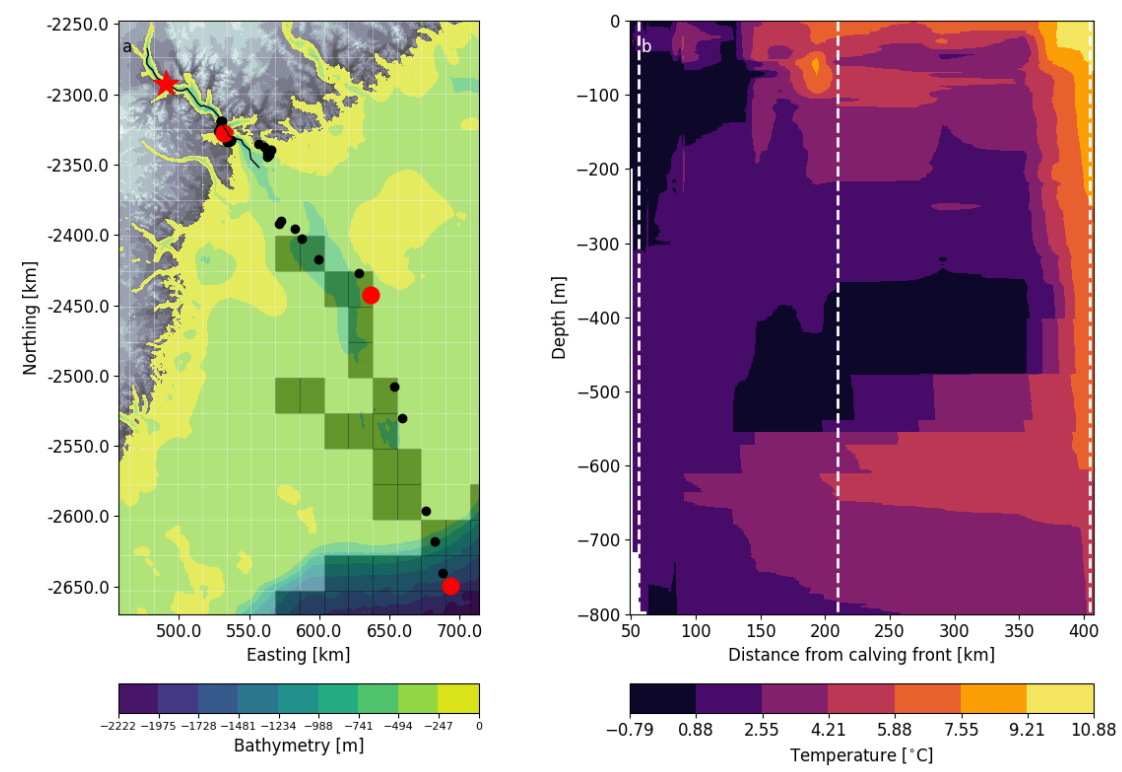

Figure S4. a) Bathymetry around Kangerlussuaq glacier (red star indicates glacier terminus). Black dots indicate the location of the CTD measurements made in September 2004. Red, thick dots show the location of CTD profiles used for the submarine melt rate calculations in the text and are indicated as white dashed lines in panel b). Closest CTD. Grid indicates the resolution of the reanalysis data and grey shaded squares show which reanalysis data points have a depth of at least $400 \mathrm{~m}$. b) Vertical temperature distribution as a function of the distance from the glacier terminus, obtained by interpolation of the CTD profiles. White dashed lines correspond to the position of the red-marked CTD positions in panel a and give for a subglacial discharge $50 \mathrm{~m}^{3} \mathrm{~s}^{-1}$ an average melt rate of $0.5,0.6$ and $3.6 \mathrm{~m} / \mathrm{d}$ (from left to right). 


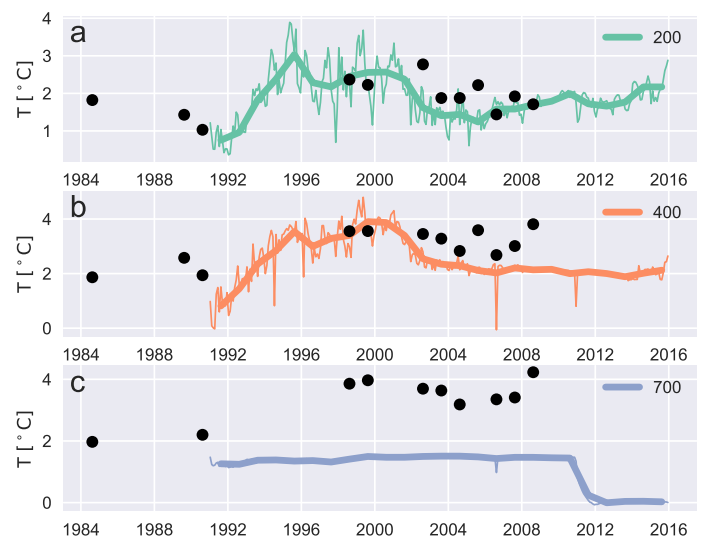

Figure S5. Monthly (thin lines) and annual mean (thick lines) of ocean temperature from reanalysis data of the closest point to fjord of Jakobshavn-Isbrae that has a minimum depth of a) $200 \mathrm{~m} \mathrm{~b}$ ) $400 \mathrm{~m}$ and c) $700 \mathrm{~m}$ depth. Location of these points differ due to the different area coverages for the corresponding depths ( $700 \mathrm{~m}$ is mostly outside of continental shelf). Black dots show CTD measurements at the same depth but inside or close to the fjord.

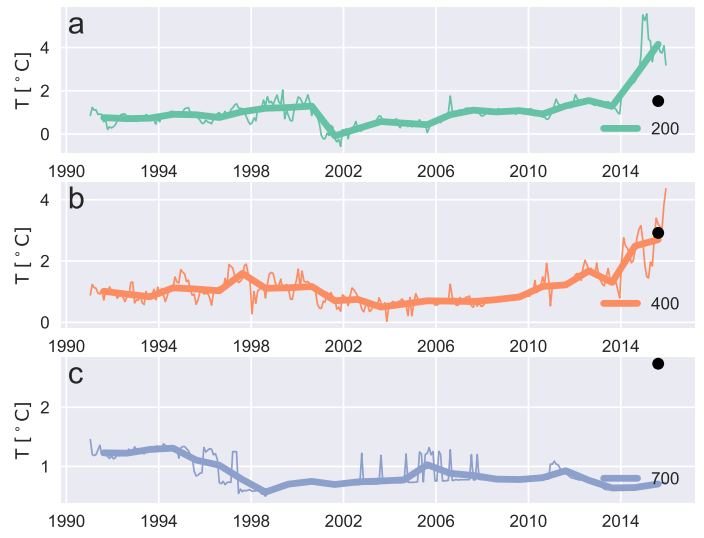

Figure S6. Same as in Fig. S5 but for Store Glacier. 


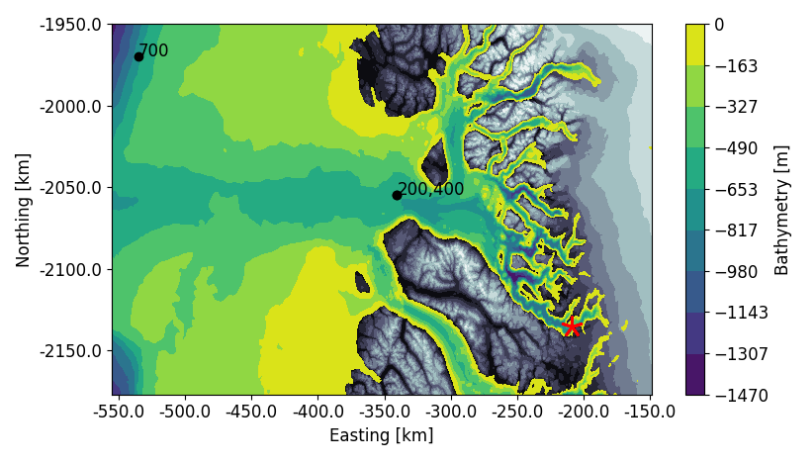

Figure S7. Bathymetry and bedrock data close to the terminus of Store Glacier (red star). The labels 200,400 and 700 indicate were the detection points of the reanalysis data closest to the glacier with the depth of $200 \mathrm{~m}, 400 \mathrm{~m}$ and $700 \mathrm{~m}$ were located.
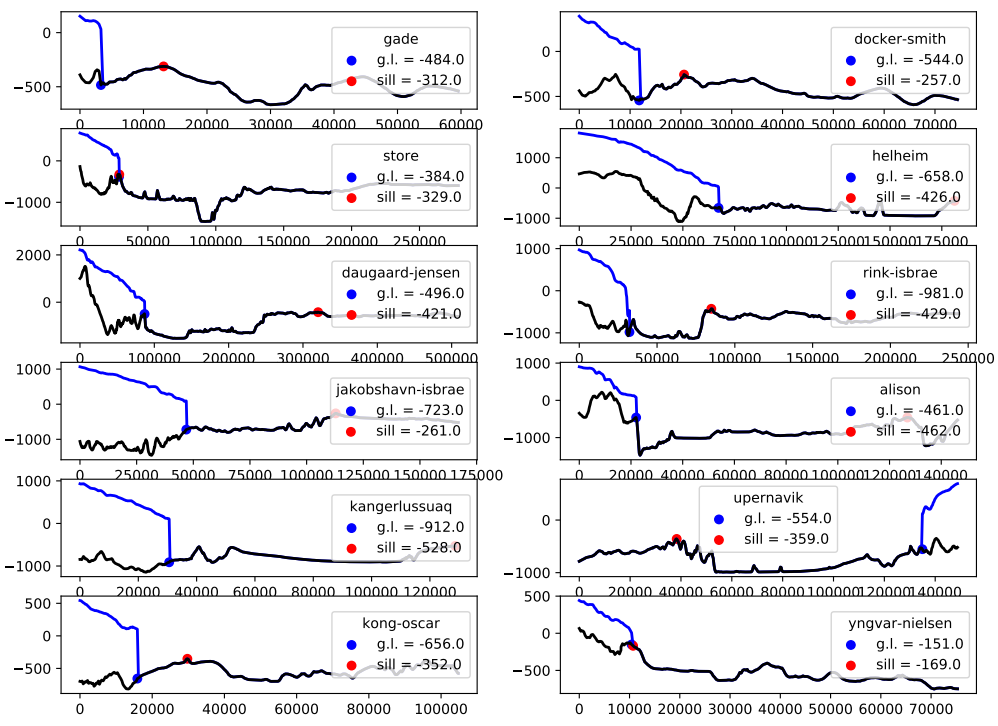

Figure S8. Centerline bathymetry for each glacier determined with BedMachine 3 data with depth determination of the grounding line (blue point) and the shallowest sill (red point). Note that we used BedMachinev2 in the experiments and only use Bedmachinev3 here for illustration since it contains an improved dataset on the bathymetry and we therefore use it to determine the shallowest sill point that might modulate the temperature profile in the fjord (see Fig. S3). We did not use, this temperature profile in any of the experiments since this increased the bias to colder temperatures. 
Table S1. Location of the temperature-profile reconstructed from reanalysis data and the derived temperature trend over 100 years for each CMIP5 model at 400m depth.

\begin{tabular}{c||c||cc||cc||cc||}
\multicolumn{1}{c||}{} & \multicolumn{2}{c||}{ Reanalysis } & \multicolumn{2}{c|}{ MPI-ESM-LR } & \multicolumn{2}{c|}{ HadGEM2-CC } & \multicolumn{2}{c||}{ GFDL-ESM2G } \\
\hline glacier name & lon,lat & \multicolumn{1}{c|}{ lon,lat } & $\frac{\Delta T}{100 a}$ & lon,lat & $\frac{\Delta T}{100 a}$ & lon,lat & $\frac{\Delta T}{100 a}$ \\
\hline Daugaard-Jensen & $-25.19,, 70.96$ & $-24.71,70.44$ & 3 & $-23.85,69.98$ & 5 & $-18.90,71.53$ & 3 \\
Helheim & $-38.1,65.17$ & $-38.13,65.07$ & 2 & $-34.83,64.97$ & 2 & -37.2964 .48 & 3 \\
Jakobshavn Isbae & $-52.35,69.17$ & $-52.61,69.05$ & 4 & -58.0667 .92 & 2 & -58.9669 .29 & 2 \\
Kangerlussuaq & $-31.66,67.89$ & $-31.66,67.89$ & 3 & -27.9666 .94 & 3 & -31.4866 .32 & 4 \\
Rink Isbrae & $-54.46,71.05$ & $-31.52,67.66$ & 3 & -59.2070 .95 & 1 & -59.2070 .95 & 2 \\
Store & $-54.41,70.94$ & $-55.39,70.89$ & 3 & -59.0470 .74 & 1 & -58.9670 .63 & 2 \\
Kong Oscar & $-61.87,75.76$ & $-60.76,75.61$ & 3 & -64.1174 .99 & 1 & -62.1775 .62 & 2 \\
Alison & $-58.83,74.6$ & $-58.83,74.60$ & 3 & -60.2973 .93 & 1 & -59.0474 .36 & 2 \\
Upernavik Isstrom & $-57.57,73.1$ & $-57.57,73.10$ & 3 & -60.0372 .81 & 1 & -58.8573 .69 & 2 \\
Yngvar Nielsen & $-64.01,75.94$ & $-63.29,75.76$ & 3 & -64.1174 .99 & 1 & -62.1775 .62 & 2 \\
Docker Smith & $-62.57,75.94$ & $-62.86,75.80$ & 3 & -64.1174 .99 & 1 & -62.1775 .62 & 2 \\
Gade Glacier & $-64.01,75.94$ & $-63.29,75.76$ & 3 & -64.1174 .99 & 1 & -62.1775 .62 & 2
\end{tabular}

\subsection{Results for present-day}

Table S2. Paramter list of pre-tuning with dynamical parameters (basal sliding coefficient $A_{s}$, velocity exponent $q$, width-scaling parameter $W_{s}$, and freshwater depth $f w d$ ), relaxation time scale $\tau$ and constant melt rate $\dot{m}$.

\begin{tabular}{c|c|c|c|c|c|c|}
\hline glacier & $q$ & $A_{s}\left[10^{-3}\right]$ & $\tau$ & $W_{s}$ & fwd & $\dot{m}[\mathrm{~m} / a]$ \\
\hline alison & 0.8 & 11.3 & 50 & 3.5 & 20 & 300 \\
daugaard-jensen & 0.25 & 284.6 & 100 & 1 & 15 & 800 \\
docker-smith & 0.8 & 25.12 & 30 & 2 & 10 & 150 \\
gade & 0.8 & 25.12 & 30 & 3.5 & 10 & 300 \\
helheim & 0.5 & 50.0 & 20 & 2.0 & 30 & 300 \\
jakobshavn-isbrae & 0.6 & 25.24 & 50 & 5 & 30 & 1090 \\
kangerlussuaq & 0.53 & 41.81 & 30 & 2 & 100 & 150 \\
kong-oscar & 0.20 & 242.85 & 20 & 1.2 & 25 & 300 \\
rink-isbrae & 0.25 & 192.9 & 20 & 1.4 & 33 & 400 \\
store & 0.8 & 10.05 & 30 & 100 & 50 & 500 \\
upernavik & 0.8 & 10.05 & 30 & 3.5 & 20 & 600 \\
yngvar-nielsen & 0.8 & 25.12 & 30 & 3.5 & 5 & 20 \\
\hline
\end{tabular}


Table S3. Parameter range of freshwater depth $f w d$ and scaling coefficient $\beta$ for the submarine melt rate and the number of feasible simulations \# for temperature profiles from CTD and reanalysis data.

\begin{tabular}{c|c|c|c|c|c|c|c|c|} 
& \multicolumn{7}{|c|}{ CTD } & \multicolumn{3}{c|}{ Rean } \\
\hline glacier & $f w d$ & $\beta$ & $\beta=1$ & $\#$ & $f w d$ & $\beta$ & $\beta=1$ & $\#$ \\
alison & $5.0-55.0$ & $0.33-3.0$ & $\mathrm{x}$ & 29 & $10.0-55.0$ & $0.33-3.0$ & - & 25 \\
daugaard-jensen & $15.0-105.0$ & $0.33-3.0$ & - & 11 & $15.0-105.0$ & $0.33-3.0$ & - & 11 \\
docker-smith & $10.0-20.0$ & $0.4-0.8$ & - & 4 & $15.0-15.0$ & $1.0-1.0$ & $\mathrm{x}$ & 1 \\
gade & $5.0-20.0$ & $0.33-3.0$ & $\mathrm{x}$ & 30 & $5.0-20.0$ & $0.4-3.0$ & $\mathrm{x}$ & 25 \\
helheim & $40.0-120.0$ & $0.33-0.33$ & - & 9 & $20.0-110.0$ & $0.33-3.0$ & $\mathrm{x}$ & 19 \\
jakobshavn-isbrae & - & - & - & - & $35.0-60.0$ & $0.33-0.5$ & - & 11 \\
kangerlussuaq & $65.0-200.0$ & $1.25-1.5$ & - & 20 & $65.0-200.0$ & $2.0-2.5$ & - & 19 \\
kong-oscar & $27.0-27.0$ & $0.8-0.8$ & - & 1 & $32.0-60.0$ & $0.33-2.0$ & - & 15 \\
rink-isbrae & $41.0-61.0$ & $0.33-0.8$ & - & 30 & $41.0-61.0$ & $0.33-1.0$ & $\mathrm{x}$ & 34 \\
store & $19.0-150.0$ & $0.33-2.0$ & $\mathrm{x}$ & 34 & $19.0-150.0$ & $0.4-2.0$ & $\mathrm{x}$ & 33 \\
upernavik & $5.0-35.0$ & $0.5-3.0$ & $\mathrm{x}$ & 15 & $15.0-30.0$ & $1.0-3.0$ & $\mathrm{x}$ & 6 \\
yngvar-nielsen & $5.0-15.0$ & $0.33-0.5$ & - & 6 & $5.0-15.0$ & $0.4-0.67$ & - & 5 \\
\hline
\end{tabular}



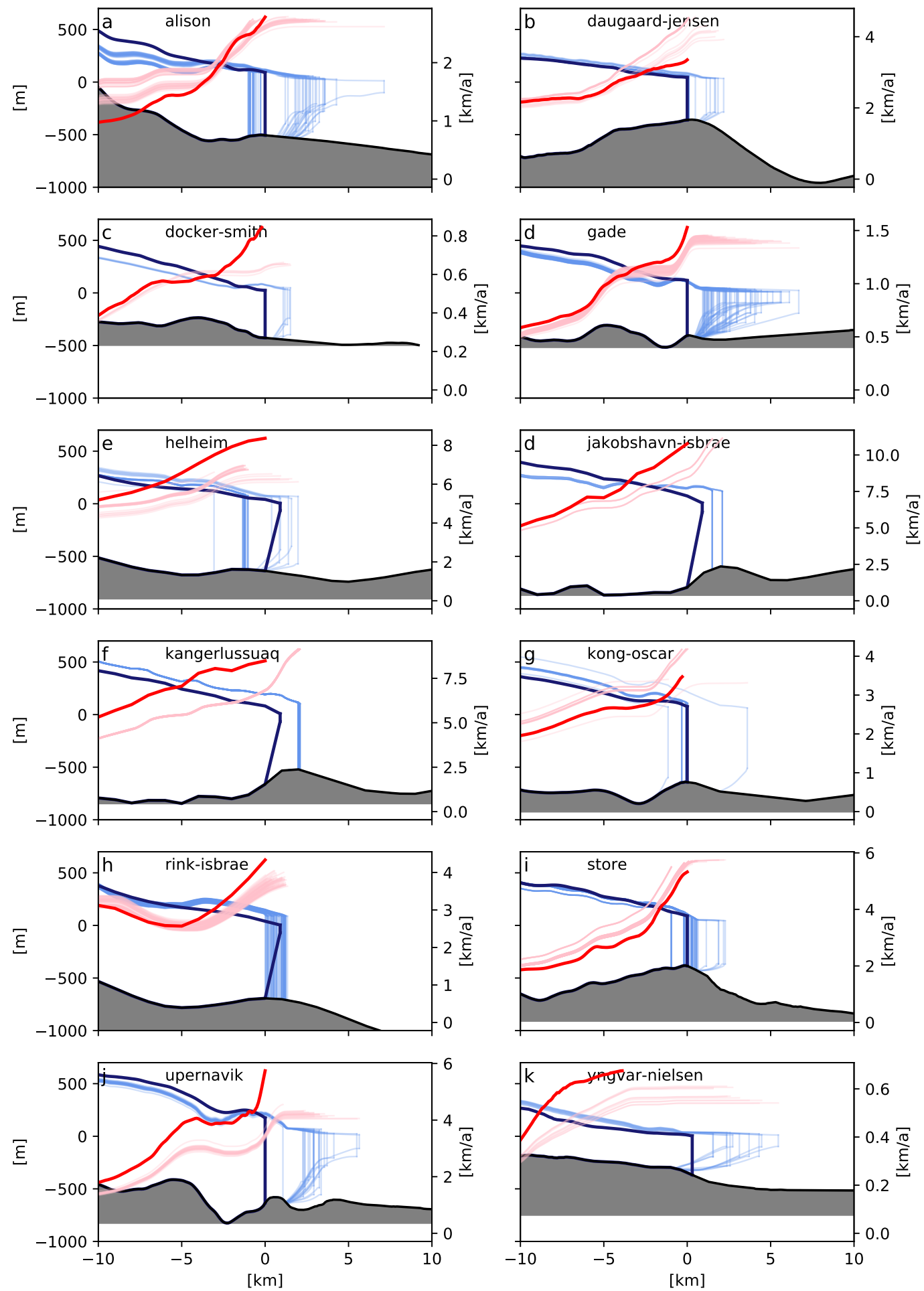

Figure S9. Glacier thickness (thick, blue) and velocity profile (thick, red) for the last $10 \mathrm{~km}$ to the grounding line from the derived geometry of the dataset published by Morlighem et al. (2014) and Rignot and Mouginot (2012).The resulting profiles of all stable states simulated by the line-plume glacier-flowline model are depicted in transparent lines. 


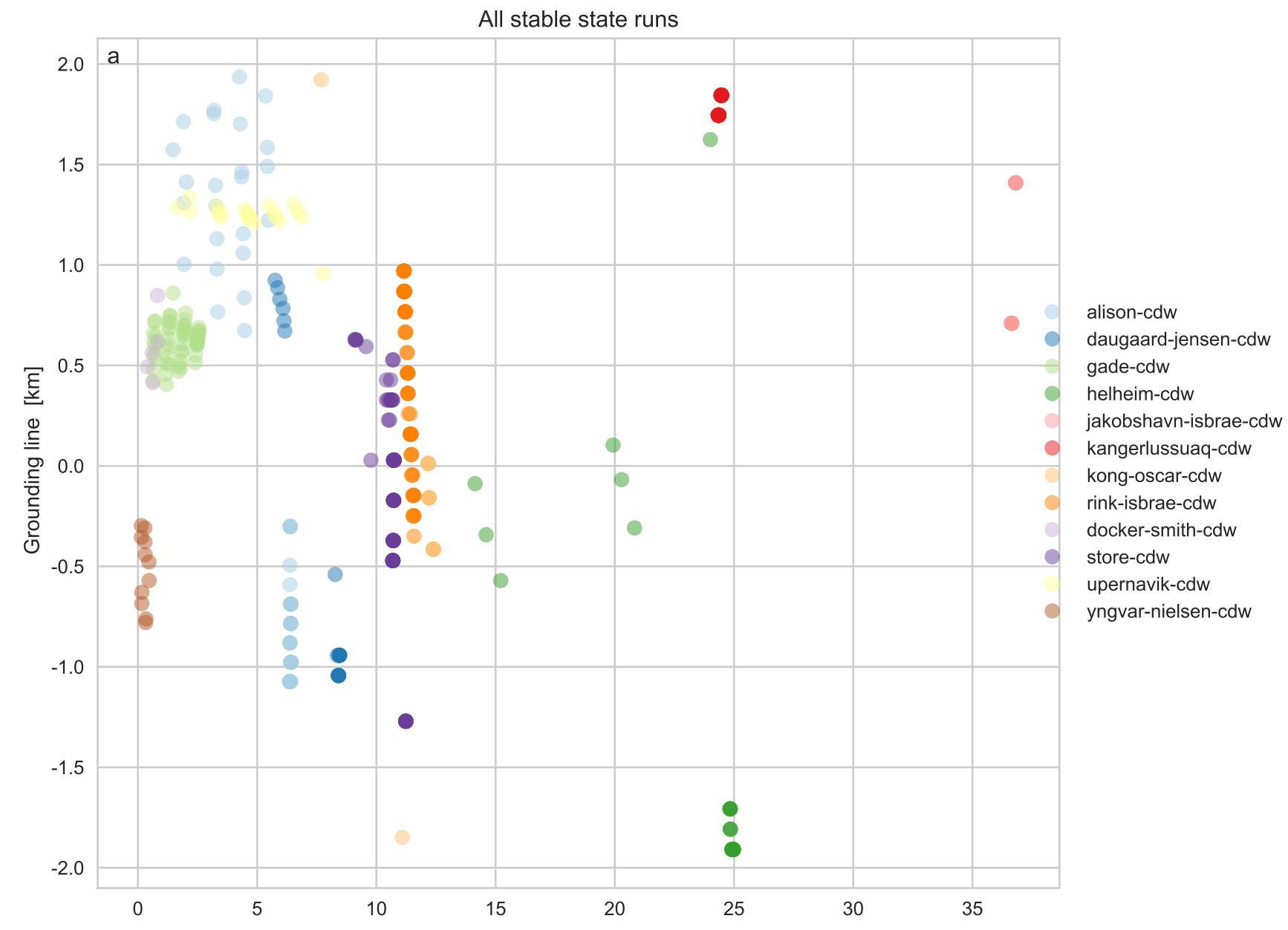

Figure S10. All considered initial stable runs depicted in their tuned grounding line position and their resulting average grounding line discharge (last 20 years) (x-axis) for the cdw-calving law. The $y$-axis illustrates the deviation to the tuned grounding line position from the one (or present day at $\mathrm{y}=0 \mathrm{~km}$ ).Each dot represent a stable run and thus different $\beta$ - $f w d$-combination, different melt-calving-partition. 


\subsection{Results for future simulations}

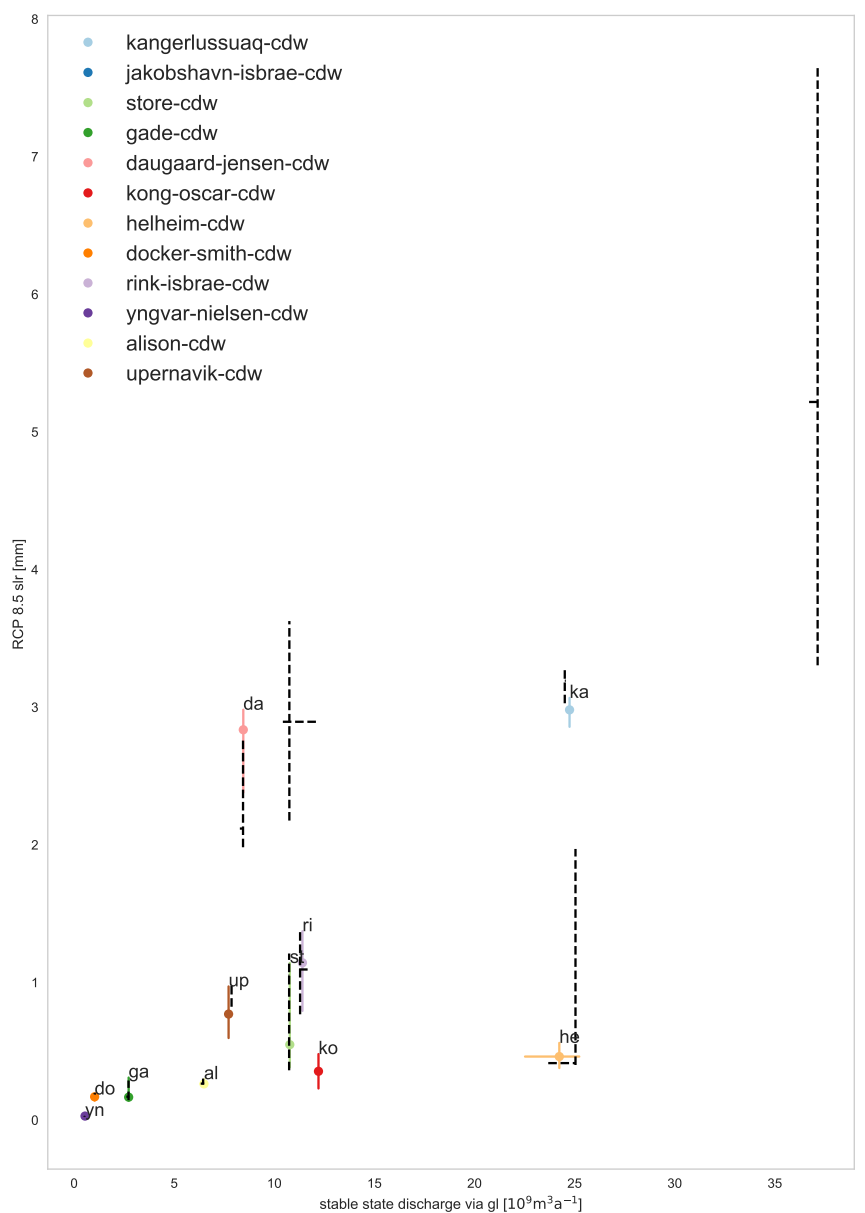

Figure S11. First till third quartile (median indicated with a dot) of the contribution to SLR for each glacier and it's dynamic response to RCP 8.5 at 2100. Future SLR-contibution is illustrated in the dependence of the present-day grounding line discharge. Simulations were run with initial temperature profile taken from CTD measurements only (solid) and reconstructed from reanalysis data (dashed). 


\subsubsection{Docker Smith}

\begin{tabular}{c|c|cc|} 
& \multicolumn{3}{|c|}{ slr $[\mathrm{mm}]$} \\
\hline glacier & median & first quartile & third quartile \\
$\Delta$ smb, $\Delta Q T_{\max }$ & 0.18 & 0.16 & 0.20 \\
$\Delta \mathrm{smb} \Delta Q T_{\min }$ & 0.18 & 0.15 & 0.18 \\
$\Delta \mathrm{smb}$ & 0.09 & 0.09 & 0.10 \\
\hline & \multicolumn{3}{|c|}{ gl retreat $[\mathrm{km}]$} \\
\hline glacier & median & first quartile & third quartile \\
$\Delta$ smb, $\Delta Q T_{\max }$ & 15.53 & 14.72 & 16.59 \\
$\Delta \mathrm{smb} \Delta Q T_{\min }$ & 14.61 & 14.11 & 16.18 \\
$\Delta \mathrm{smb}$ & 5.16 & 4.57 & 5.32
\end{tabular}

\subsubsection{Jakobshavn Isbrae}

\begin{tabular}{c|c|cc|} 
& \multicolumn{3}{|c|}{ slr $[\mathrm{mm}]$} \\
\hline glacier & median & first quartile & third quartile \\
$\Delta$ smb, $\Delta Q T_{\max }$ & 5.31 & 4.05 & 7.95 \\
$\Delta$ smb $\Delta Q T_{\min }$ & 4.45 & 3.39 & 7.57 \\
$\Delta \mathrm{smb}$ & 1.36 & 0.87 & 3.33 \\
\hline \multicolumn{3}{|c|}{ gl retreat $[\mathrm{km}]$} \\
\hline glacier & median & first quartile & third quartile \\
$\Delta$ smb, $\Delta Q T_{\max }$ & 38.71 & 27.65 & 41.00 \\
$\Delta$ smb $\Delta Q T_{\min }$ & 29.43 & 18.34 & 40.47 \\
$\Delta$ smb & 6.62 & 0.09 & 26.27
\end{tabular}

\subsubsection{Helheim}

\begin{tabular}{c|c|cc|} 
& \multicolumn{3}{|c|}{ slr $[\mathrm{mm}]$} \\
\hline glacier & median & first quartile & third quartile \\
$\Delta$ smb, $\Delta Q T_{\max }$ & 0.58 & 0.41 & 0.75 \\
$\Delta$ smb $\Delta Q T_{\min }$ & 0.38 & 0.36 & 0.54 \\
$\Delta \mathrm{smb}$ & 0.29 & 0.29 & 0.30 \\
\hline & \multicolumn{3}{|c|}{ gl retreat $[\mathrm{km}]$} \\
\hline glacier & median & first quartile & third quartile \\
$\Delta$ smb, $\Delta Q T_{\max }$ & 8.70 & 1.45 & 9.27 \\
$\Delta \mathrm{smb} \Delta Q T_{\min }$ & 1.01 & 0.77 & 3.63 \\
$\Delta \mathrm{smb}$ & 0.23 & 0.17 & 0.26
\end{tabular}




\begin{tabular}{c|c|cc|} 
& \multicolumn{3}{|c|}{ slr $[\mathrm{mm}]$} \\
\hline glacier & median & first quartile & third quartile \\
$\Delta$ smb, $\Delta Q T_{\max }$ & 2.78 & 2.42 & 2.98 \\
$\Delta$ smb $\Delta Q T_{\min }$ & 2.12 & 2.07 & 2.84 \\
$\Delta \mathrm{smb}$ & 1.17 & 1.16 & 1.17 \\
\hline & \multicolumn{3}{|c|}{ gl retreat $[\mathrm{km}]$} \\
\hline glacier & median & first quartile & third quartile \\
$\Delta$ smb, $\Delta Q T_{\max }$ & 62.21 & 34.89 & 65.56 \\
$\Delta \mathrm{smb} \Delta Q T_{\min }$ & 29.10 & 28.94 & 61.11 \\
$\Delta \mathrm{smb}$ & 22.68 & 22.68 & 22.68
\end{tabular}

\subsubsection{Gade}

\begin{tabular}{c|c|cc|} 
& \multicolumn{3}{|c|}{ slr $[\mathrm{mm}]$} \\
\hline glacier & median & first quartile & third quartile \\
$\Delta$ smb, $\Delta Q T_{\max }$ & 0.20 & 0.16 & 0.33 \\
$\Delta$ smb $\Delta Q T_{\min }$ & 0.16 & 0.14 & 0.26 \\
$\Delta \mathrm{smb}$ & 0.09 & 0.09 & 0.10 \\
\hline & \multicolumn{3}{|c|}{ gl retreat $[\mathrm{km}]$} \\
\hline glacier & median & first quartile & third quartile \\
$\Delta$ smb, $\Delta Q T_{\max }$ & 8.20 & 4.66 & 15.84 \\
$\Delta$ smb $\Delta Q T_{\min }$ & 5.19 & 4.51 & 12.67 \\
$\Delta \mathrm{smb}$ & 3.12 & 3.07 & 3.16
\end{tabular}

\subsubsection{Kangerlussuaq}

\begin{tabular}{c|c|cc|} 
& \multicolumn{3}{|c|}{ slr $[\mathrm{mm}]$} \\
\hline glacier & median & first quartile & third quartile \\
$\Delta \mathrm{smb}, \Delta Q T_{\max }$ & 3.19 & 3.08 & 3.26 \\
$\Delta \mathrm{smb} \Delta Q T_{\min }$ & 2.97 & 2.76 & 3.00 \\
$\Delta \mathrm{smb}$ & 0 & 0 & 0 \\
\hline & \multicolumn{3}{|c|}{ gl retreat $[\mathrm{km}]$} \\
\hline glacier & median & first quartile & third quartile \\
$\Delta \mathrm{smb}, \Delta Q T_{\max }$ & 28.52 & 28.52 & 28.61 \\
$\Delta \mathrm{smb} \Delta Q T_{\min }$ & 28.52 & 28.44 & 28.52
\end{tabular}




\subsubsection{Yngvar Nielsen}

\begin{tabular}{c|c|cc|} 
& \multicolumn{3}{|c|}{ slr $[\mathrm{mm}]$} \\
\hline glacier & median & first quartile & third quartile \\
$\Delta$ smb, $\Delta Q T_{\max }$ & 0.03 & 0.03 & 0.03 \\
$\Delta$ smb $\Delta Q T_{\min }$ & 0.03 & 0.03 & 0.03 \\
$\Delta \mathrm{smb}$ & 0.02 & 0.02 & 0.02 \\
\hline & \multicolumn{3}{|c|}{ gl retreat $[\mathrm{km}]$} \\
\hline glacier & median & first quartile & third quartile \\
$\Delta$ smb, $\Delta Q T_{\max }$ & 5.14 & 4.73 & 5.51 \\
$\Delta \mathrm{smb} \Delta Q T_{\min }$ & 4.23 & 3.93 & 4.66 \\
$\Delta \mathrm{smb}$ & 2.65 & 2.51 & 2.74
\end{tabular}

\subsubsection{Alision}

\begin{tabular}{c|c|cc|} 
& \multicolumn{3}{|c|}{ slr $[\mathrm{mm}]$} \\
\hline glacier & median & first quartile & third quartile \\
$\Delta$ smb, $\Delta Q T_{\max }$ & 0.27 & 0.26 & 0.30 \\
$\Delta$ smb $\Delta Q T_{\min }$ & 0.26 & 0.26 & 0.29 \\
$\Delta \mathrm{smb}$ & 0.21 & 0.17 & 0.22 \\
\hline & \multicolumn{3}{|c|}{ gl retreat $[\mathrm{km}]$} \\
\hline glacier & median & first quartile & third quartile \\
$\Delta$ smb, $\Delta Q T_{\max }$ & 9.26 & 8.70 & 10.78 \\
$\Delta \mathrm{smb} \Delta Q T_{\min }$ & 9.17 & 8.69 & 10.68 \\
$\Delta \mathrm{smb}$ & 8.51 & 0.78 & 8.60
\end{tabular}

\subsubsection{Kong Oscar}

\begin{tabular}{c|c|cc|} 
& \multicolumn{3}{|c|}{ slr $[\mathrm{mm}]$} \\
\hline glacier & median & first quartile & third quartile \\
$\Delta$ smb, $\Delta Q T_{\max }$ & 3.35 & 2.88 & 4.13 \\
$\Delta \mathrm{smb} \Delta Q T_{\min }$ & 2.55 & 1.79 & 3.28 \\
$\Delta \mathrm{smb}$ & -0.10 & -0.11 & -0.10 \\
\hline & \multicolumn{3}{|c|}{ gl retreat $[\mathrm{km}]$} \\
\hline glacier & median & first quartile & third quartile \\
$\Delta$ smb, $\Delta Q T_{\max }$ & 18.63 & 17.65 & 19.40 \\
$\Delta \mathrm{smb} \Delta Q T_{\min }$ & 15.78 & 14.33 & 17.23 \\
$\Delta \mathrm{smb}$ & 0.00 & 0.00 & 0.00
\end{tabular}




\subsubsection{Rink Isbare}

\begin{tabular}{c|c|cc|} 
& \multicolumn{3}{|c|}{ slr $[\mathrm{mm}]$} \\
\hline glacier & median & first quartile & third quartile \\
$\Delta \mathrm{smb}, \Delta Q T_{\max }$ & 1.14 & 0.87 & 1.38 \\
$\Delta \mathrm{smb} \Delta Q T_{\min }$ & 1.07 & 0.78 & 1.26 \\
$\Delta \mathrm{smb}$ & 0 & 0 & 0 \\
\hline glacier & \multicolumn{3}{|c|}{ gl retreat $[\mathrm{km}]$} \\
$\Delta \mathrm{smb}, \Delta Q T_{\max }$ & 11.14 & 10.96 & 11.27 \\
$\Delta \mathrm{smb} \Delta Q T_{\min }$ & 11.00 & 10.81 & 11.11 \\
$\Delta \mathrm{smb}$ & 0 & 0 & 0
\end{tabular}

\subsubsection{Upernavik North}

\begin{tabular}{c|c|cc|} 
& \multicolumn{3}{|c|}{ slr $[\mathrm{mm}]$} \\
\hline glacier & median & first quartile & third quartile \\
$\Delta$ smb, $\Delta Q T_{\max }$ & 0.92 & 0.70 & 1.00 \\
$\Delta$ smb $\Delta Q T_{\min }$ & 0.75 & 0.58 & 0.93 \\
$\Delta \mathrm{smb}$ & 0.28 & 0.28 & 0.28 \\
\hline \multicolumn{3}{|c|}{ gl retreat $[\mathrm{km}]$} \\
\hline glacier & median & first quartile & third quartile \\
$\Delta$ smb, $\Delta Q T_{\max }$ & 17.62 & 14.52 & 17.82 \\
$\Delta$ smb $\Delta Q T_{\min }$ & 17.02 & 7.11 & 17.62 \\
$\Delta$ smb & 5.52 & 5.52 & 5.52
\end{tabular}

\subsubsection{Store}

\begin{tabular}{c|c|cc|} 
& \multicolumn{3}{|c|}{ slr $[\mathrm{mm}]$} \\
\hline glacier & median & first quartile & third quartile \\
$\Delta \mathrm{smb} \Delta Q T_{\min }$ & 1.05 & 0.55 & 1.16 \\
$\Delta \mathrm{smb}, \Delta Q T_{\max }$ & 0.87 & 0.46 & 1.18 \\
$\Delta \mathrm{smb}$ & 0.76 & 0.75 & 0.76 \\
\hline \multicolumn{3}{|c|}{ gl retreat $[\mathrm{km}]$} \\
\hline glacier & median & first quartile & third quartile \\
$\Delta \mathrm{smb} \Delta Q T_{\min }$ & 17.55 & 12.06 & 23.21 \\
$\Delta \mathrm{smb}, \Delta Q T_{\max }$ & 17.44 & 4.72 & 23.25 \\
$\Delta \mathrm{smb}$ & 16.52 & 16.02 & 16.52
\end{tabular}




\section{References}

Calov, R., Beyer, S., Greve, R., Beckmann, J., Willeit, M., Kleiner, T., Rückamp, M., Humbert, A., and Ganopolski, A.: Simulation of the future sea level contribution of Greenland with a new glacial system model, The Cryosphere Discussions, 2018, 1-37, https://doi.org/10.5194/tc-2018-23, https://www.the-cryosphere-discuss.net/tc-2018-23/, 2018.

Inall, M. E., Murray, T., Cottier, F. R., Scharrer, K., and Boyd, T. J.: Oceanic heat delivery via Kangerdlugssuaq Fjord to the south-east Greenland ice sheet, Journal of Geophysical Research : Oceans, pp. 631-645, https://doi.org/10.1002/2013JC009295.Received, 2014.

Morlighem, M., Rignot, E., Mouginot, J., Seroussi, H., and Larour, E.: Deeply incised submarine glacial valleys beneath the Greenland ice sheet, Nature Geoscience, 7, 418-422, https://doi.org/10.1038/ngeo2167, http://www.nature.com/doifinder/10.1038/ngeo2167, 2014.

10 Rignot, E. and Mouginot, J.: Ice flow in Greenland for the International Polar Year 2008-2009, Geophys. Res. Lett., 39, L11 501, https://doi.org/10.1029/2012GL051634, 2012.

Schaffer, J., von Appen, W. J., Dodd, P. A., Hofstede, C., Mayer, C., de Steur, L., and Kanzow, T.: Warm water pathways toward Nioghalvfjerdsfjorden Glacier, Northeast Greenland, Journal of Geophysical Research: Oceans, 122, 4004-4020, https://doi.org/10.1002/2016JC012462, 2017.

15 Straneo, F. and Heimbach, P.: North Atlantic warming and the retreat of Greenland's outlet glaciers., Nature, 504, 36-43, https://doi.org/10.1038/nature12854, http://www.ncbi.nlm.nih.gov/pubmed/24305146, 2013.

Straneo, F., Sutherland, D. a., Holland, D., Gladish, C., Hamilton, G. S., Johnson, H. L., Rignot, E., Xu, Y., and Koppes, M.: Characteristics of ocean waters reaching greenland's glaciers, Annals of Glaciology, 53, 202-210, https://doi.org/10.3189/2012AoG60A059, 2012. 